The University of San Francisco

USF Scholarship: a digital repository @ Gleeson Library | Geschke Center

$7-2-2020$

Brick-and-Platform: Listing Labor in the Digital Vintage Economy

Tamara Kneese

Michael Palm

Follow this and additional works at: https://repository.usfca.edu/ms

Part of the Advertising and Promotion Management Commons, and the Marketing Commons 


\title{
Brick-and-Platform: Listing Labor in the Digital Vintage Economy
}

Social Media + Society July-September 2020: I-II (C) The Author(s) 2020 Article reuse guidelines: sagepub.com/journals-permissions DOI: I0.II77/2056305I20933299 journals.sagepub.com/home/sms (S)AGE

\author{
Tamara Kneese ${ }^{1}$ (D) and Michael Palm²
}

\begin{abstract}
Vintage goods are valued for their nostalgic association with pre-digital modes of production, but their contemporary trafficking is increasingly organized by processes of platformization. The central component of what we call "listing labor in the digital vintage economy" is the online display of collectible merchandise, but listing labor also entails promoting sellers' brands on social media and using sales platforms and other logistical media to manage inventory, process transactions, and handle shipments. Listing labor is performed by branded merchants and their employees alongside independent entrepreneurs. The digital vintage economy connects brick-and-mortar shops and resale supply chains organized around flea markets, thrift shops and charity bins, estate sales, and consigners, to online clearinghouses like eBay and Craigslist, and to social media and payment apps. In this article, we argue that listing labor in the digital vintage economy further develops the concept of "platform labor." We focus on vintage clothes and vinyl records, dominated by women and men, respectively, to help us analyze divisions of listing labor organized by gender, race, age, and class. We draw upon 20 semi-structured interviews with shop owners and employees and on participant observation in independently owned clothing boutiques and record stores in several US cities. The digital vintage economy provides another angle for understanding how identity-based distinctions affect the opportunities associated with platform labor, and our account of listing labor highlights the need for studies of platformization that analyze its effects on specific local economies as well as on job markets and commercial sectors.
\end{abstract}

\section{Keywords}

social media, self-branding, retail, platformization, digital labor

Old-fashioned artifacts like vintage clothes and vinyl records are valued in no small part for their pre-digital modes of production. At the same time, niche markets for vintage goods are increasingly facilitated through dedicated platforms, which exponentially expand the geographic reach of local merchants and individual sellers. On Discogs, for instance, thousands of sellers based in 85 countries list over 33 million vinyl records (as of August 2019). Shoppers can sort available copies by price, condition, age, and location; users who keep a "want list" are alerted as soon as a copy is posted for sale, and buyers and sellers are expected to leave one another reviews. Vinyl record sales are fueled by the speed and efficiency of algorithms and search engines, yet sites like Discogs are often omitted from larger conversations about the platform economy. One fundamental aspect of "platformization" is an increasingly "centralized, proprietary mode of cultural production" and exchange (Nieborg \& Poell, 2018, p. 4279); in niche vintage markets, this centralization is also specialized, meaning that platforms like Discogs and Etsy have supplanted online clearinghouses like eBay and Craigslist as the best places to buy and sell collectibles like rare records and what insiders refer to as "true vintage" clothing. The circulation of vintage styles and formats is organized, however ironically, by the very technology from which they purportedly offer an alternative.

We refer to the transactional platforms and online storefronts for old-fashioned commodities like vinyl records and vintage clothes as the digital vintage economy, and we describe the tasks and responsibilities of selling therein as listing labor. The central component of listing labor in the digital vintage economy is the online display of aged merchandise. Customers are unable to assess items in person, so sellers tell enticing stories about them-presented alongside flattering images - to convince potential buyers of their quality, authenticity, and rarity. The listing labor for vintage goods is directly related to their status as historical objects, with wear and tear that has to be accounted for. Product

\footnotetext{
'University of San Francisco, USA

${ }^{2}$ The University of North Carolina at Chapel Hill, USA

Corresponding Author:

Tamara Kneese, University of San Francisco, 21 30 Fulton Street, San Francisco, CA 94II7, USA.

Email: tkneese@usfca.edu
} 
images and detailed descriptions are the lifeblood of online retail sectors, and their aesthetic stakes are heightened in the digital vintage economy, where it is more difficult for shoppers to verify an item's condition online than it would be in a store. The age and often the fragility of vintage goods requires handling, cleaning, and packing techniques that are elaborate, rigorous, and verifiable; in the digital vintage economy, the risks of damaging rare items in transit are greater and the costs of returns are higher than they are for mass-produced commodities sold online. Listing labor also includes promoting and publicizing sellers' brands on social media and digital storefronts, as well as using sales platforms and other logistical media to manage inventory, facilitate transactions, and arrange shipments. The niche markets comprising the digital vintage economy thrive on a gendered artisanal and entrepreneurial imaginary that underpins what is in fact mundane, physical labor-from cleaning and sorting merchandise or sweeping floors to carrying boxes and moving backstock from warehouses to the selling floor. Listing labor in the digital vintage economy is performed by branded merchants and their employees along with independent entrepreneurs flipping collectibles to make a living, fund their own vintage habit, or both.

If the "platformization of cultural production" is a process by which "cultural commodities become fundamentally 'contingent', that is increasingly modular in design and continuously reworked and repackaged, informed by datafied user feedback," then the digital vintage economy provides a useful countervailing example, in that its commodities are valued for their agedness, for a contingency that is more historical and accumulative on a longer timescale than that typically associated with contemporary modes of data-driven cultural production, distribution, and exchange (Nieborg \& Poell, 2018, p. 4275). The digital vintage economy also offers an instructive space for documenting how platforms are affecting local merchants and brick-and-mortar shops (see Figure 1), and for understanding how their platformization intersects with other trends, including gentrification, rising commercial rents, and the collapse of retail marketplaces in many major cities (Smith, 1996; Zukin et al., 2009).

We argue that the digital vintage economy expands and further develops the category of "platform labor" (van Doorn, 2017). Service work's "history of inequality and subordination extends into the networked present of the ondemand economy, whose success depends on the algorithmic intensification of established modes of exploitation" (van Doorn, 2017, p. 900). The digital vintage economy is a particularly noteworthy site of this intensification because vintage goods are valued for their perceived distance from contemporary trends of cultural production and commodification. Listing labor animates the valuing of vintage goods, and so provides an interesting counterpart to practices of algorithmically informed curation described in this issue (Bonini \& Gandini, 2019) and beyond (Seaver, 2017). Our conception of listing labor is informed by historical

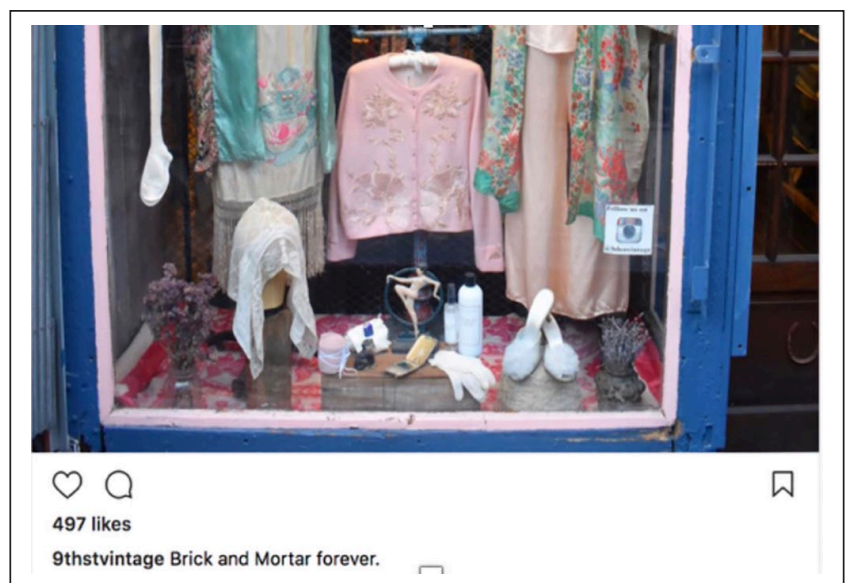

Figure I. "Brick and Mortar forever." Instagram post of 9th Street Haberdashery storefront in NYC, 24 January 2018. 9th Street sells rare clothing from the late 19th and early 20th centuries. Note the "Follow us on Instagram" icon in the window.

trajectories of "taste-making" among retail service workers, whose interactions with shoppers become part of the commodities for sale (reflected more reliably in prices than in wages). Listing labor provides a different perspective on how platformization is changing the "relationship [s] between value and visibility, when it is mediated through the problem of labor as at once a commodity and a lived experience" (van Doorn, 2017, p. 898). Employing some of the same strategies as influencers and bloggers, digital vintage economy workers hawk physical goods while simultaneously branding their storefronts and often themselves (Duffy, 2017; Duffy \& Hund, 2015; Marwick, 2013).

We develop the category of listing labor by contextualizing it within histories of retail service work and trends of cultural production and consumption, and we situate the digital vintage economy within studies of online commerce and platformization. We describe vintage clothes and vinyl records as two prominent sectors of the digital vintage economy, dominated by women and men, respectively, to help us analyze divisions of listing labor organized by gender, sexuality, race, age, class, and geography.

\section{Methodology}

To delineate listing labor in the digital vintage economy as a unique yet representative mode of platformization, we engage historical and ethnographic studies of retail service jobs (Benson, 1988; Sherman, 2007) and critiques of cultural labor within contemporary capitalism (Gill \& Pratt, 2008; McRobbie, 2010; Srnicek, 2016). We have engaged in participant observation in record stores and clothing boutiques located in a number of cities and towns across the United States, including New York, Chicago, Portland, San Francisco, Oakland, and Durham and Chapel Hill, NC. 
We consider the gendered and racialized subcultures of collecting vintage clothing and/or vinyl records. Vinyl and vintage clothing boutiques are often located in the same neighborhoods, even on the same blocks in urban centers or cultural districts, and some shops sell vintage clothing, accessories, and furniture as well as records. Popular record collecting genres, such as rock, jazz, and blues, tend to attract a predominately white male fan base (Palm, 2019, pp. 649651; Petrusich, 2014; Straw, 1997), whereas vintage clothing is associated with femme subcultures, such as pinup fashion, and the performativity of whiteness (Dahl, 2014; Gajjala, 2015) entwined with a fetishization of racialized novelty prints and home goods (i.e., Tiki bar accessories). In our broader project about the digital vintage economy, we are interested in how nostalgia for earlier periods and kitsch collecting intersect with assumptions about gender, sexuality, race, class, and privilege; here, we focus more narrowly on how vintage consumption trends contribute to the organizations and divisions of listing labor.

Site visits provide a window into how the digital vintage economy functions in various cities, which are dealing with their own versions of gentrification, affordable housing crises, and rising commercial rents. Independently owned vintage and vinyl shops provide an illuminating look at how the shift to online sales and platform labor are affecting local economies and cultures. We have conducted 20 semi-structured interviews with key informants across the United States, including shop owners (10) and employees (5), as well as sellers who closed their brick-and-mortar stores (5), to better understand how platformization is affecting vintage retail merchants as they conduct business online and offline. These interviews directly inform our analysis, and we also quote several informants' online posts. Interview subjects represented a range of identities and experiences related to position, gender, race, class, and age. Tellingly, nearly every record store owner we have interviewed is a white man, and every clothing boutique owner we have interviewed is a white woman. The employees who work in record stores and clothing boutiques are more evenly divided by gender and race, while three manwoman couples run vintage shops selling both records and clothing. Participant observation included shadowing workers in shops and working behind store counters while engaging in the purchasing and selling of collectibles in stores and online.

In addition to visiting physical stores, we followed branded sellers for several months on Etsy and Discogs and on social media, primarily Instagram and Facebook. All of our interview subjects use a combination of Instagram/Etsy or Discogs, with PayPal as the most common method of payment. There are secondhand specific apps and websites individual sellers may use (e.g., Reverb and Popsike for records; Vinted and Poshmark for clothes) and many sellers also use eBay and Craigslist to buy, sell, and flip secondhand merchandise, but here we focus on the platforms that our interview subjects use to supplement or replace their brick-and-mortar stores.

\section{Delineating Listing Labor}

A defining feature of listing labor is the cataloging of merchandise online. That central task entails an assortment of other laboring activities, including inspecting, describing, and photographing items for sale; procuring and managing inventory; and packing and shipping goods sold. Whether or not merchants maintain a brick-and-mortar outlet, the primary worksites for listing labor in the digital vintage economy are transactional platforms and online storefronts, in addition to social media sites utilized for promotion and sales. At the same time, listing labor in the digital vintage economy is no less embodied than traditional modes of retail employment in the warehouse and on the selling floor. Listing labor is always performed by workers situated offline, while on the bus and in line at the post office as well as in more formal worksites. Listing labor happens in virtually every sector of retail sales today, and we focus on the digital vintage economy as a particularly revealing example of platformization.

Just as the performance of listing labor necessarily bridges online and offline worksites, it is also patently contemporary yet deeply historical. Several trajectories of retail sales sectors culminate in listing labor. For starters, posting merchandise for sale online is a fairly direct descendent of mail-order catalogs and print advertisements ranging from billboards to coupons. The more revealing differences between the digital aspects of listing labor and its predecessors, including storefront window displays, catalogs, and print ads, involve the technology and how it enables "flexible" employees and entrepreneurs to present their own merchandise, instead of hiring professional photographers, models, and graphic designers. DIY versions of countercultural listing labor exist in music zines that sell cassettes or records, or even earlier examples like the Whole Earth Catalog (Turner, 2006). However, when it comes to branded digital storefronts, the data capture and analysis facilitated by platforms also engenders tighter and more revealing feedback loops between display and browsing; Etsy alerts browsers to the number of people looking at the same item and how many others have the singular item in their carts. In turn, platformed merchandise requires more rigorous maintenance of inventory by employees and allows for more intricate surveillance of employees by their employers and customers alike as everyone's actions are monitored and can be tracked in real time (Stark \& Levy, 2018).

Listing labor involves the display of merchandise for shoppers to browse and search online, instead of or in addition to on the selling floor. By definition, listing labor entails the physical separation of buyers and sellers. And, again, this separation is in many ways new and unique to the Internet, while also continuing and even intensifying socioeconomic divisions among and between retail workers and consumers. As labor historian Louis Hyman has noted, the Sears Roebuck catalog was revolutionary in the Jim Crow South, in that it 
allowed Black consumers to shop remotely (MacLellan, 2018). Despite these democratizing developments, the new distance between buyer and seller rendered modes of retail labor and its industrial supply chains newly invisible and, therefore, as possible pockets of exploitation. The separation of service workers from their employers' customers is an established mode of labor management in the contemporary service economy, offline as well as online. For example, guests' experiences in luxury hotels are predicated on the apparent absence of certain employees (e.g., housekeeping staff, short order cooks) as much as the presence of others (e.g., concierges and live musicians) (Sherman, 2007). Similarly, the history of self-service consumption is littered with back-office workers whose logistical support makes possible the seemingly automated consumer tasks like ATM transactions and self-checkout (Palm, 2017).

Online sales in the digital vintage economy are facilitated by modes of labor that often embody absence and presence in the same worker. Listing labor allows shoppers to browse away from the watchful eye of sellers, yet responsiveness and availability have become hallmarks of the digital vintage economy and a key selling point for online merchants over competitors with only brick-and-mortar outlets. In the digital vintage economy, interactions between workers and shoppers take place via email or direct message and are mediated by social media and chat apps, as well as a host of support platforms like PayPal and older commercial services like the US Postal Service and FedEx. Beyond discrete apps and platforms, listing labor in the digital vintage economy demonstrates how platform-ization is transforming the internet writ large as a commercial technology.

As we elaborate in subsequent sections, online reviews and ratings are essential to the digital vintage economy, within which consumers' habits and desires inform the management of listing labor at an affective and interactive level. Meanwhile, interactions with hip clerks in brick-and-mortar boutiques still lend pleasure and appeal ("value-added") to the shopping experience and, therefore, the prices of merchandise (Benson, 1988). This is especially true for old-fashioned products like vintage clothing and vinyl records. The secondhand aspects of listing labor are connected to older histories of peer-to-peer exchange, like record and clothing swaps and flea markets, as well as other venues for the buying, selling, and trading of used goods, including antique stores. Emerging from this larger culture, clerks in record stores and vintage clothing boutiques are expected to be knowledgeable and passionate about their wares before being hired, with access to desirable goods and culture serving as a subsidy for low wages (Williams \& Connell, 2010). However, the hanging out and talking shop that have long animated the experience of working in such stores is more constricted now by online sales, promotion, and communication: clerks' traditional down-time tasks is redirected from pricing and stocking merchandise and monitoring customers to tracking and updating unique inventory online, posting on social media, answering emails, and arranging shipments; workers' attention is divided between the selling floor and the screen.

\section{Valuing Vintage}

The digital vintage economy is part of a larger wave of artisanal nostalgia, mobilized in response to post-Fordist modes of production and based on re-imaginings of 19th and 20th century craft labor practices that often elide their gender, sexual, racial, and class politics (Gajjala, 2015). Vintage clothing and vinyl records entail older ways of looking, listening, and being, not just as consumption and leisure, but as lifestyle, identity, ethics, and even new forms of labor (Ayres, 2019; Cassidy \& Bennett, 2012; Clark \& Palmer, 2005; Harvey, 2017; Thorén et al., 2017). In this section, we follow feminist critiques of post-Fordism (Gill \& Pratt, 2008; McRobbie, 2010) and the "digital double bind" (Duffy \& Hund, 2015) by describing how nostalgia and platformization cooperate to produce the mutually constitutive authenticity of goods and sellers in the digital vintage economy.

The popularity of vintage clothing and vinyl records has grown steadily since the turn of the century as younger generations seek out authentic engagement with culture. Invoking Walter Benjamin's canonical critique of mechanical reproduction, Susan Luckman (2013) has theorized "the aura of the analogue in a digital age." Etsy is the most familiar vintage platform, where stores, collectors, and entrepreneurs display and sell their wares. Luckman (2013) notes that Etsy, while founded by Silicon Valley men and backed by venture capitalists, is flooded with young women entrepreneurs selling craft items that take on an aura of the handmade regardless of how they are produced. Records are mass produced, yet similarly "signify authenticity to today's purchasers" (Barry, 2014). Collectible records and vintage clothing have accumulated histories that further enhance their Benjaminian aura. In the digital vintage economy, sellers conjure the materiality of commodities, imbuing them with a power beyond their physical attributes or commercial value alone (Appadurai, 1988). To foster online sales, vintage clothing stores post images of the designer labels within high-ticket vintage pieces and close-ups of beadwork or authenticate their Bakelite jewelry through burn tests. Along the same lines, vinyl vendors verify a record's authenticity by scrutinizing etched serial numbers on the record itself, as well as the particular designs and color patterns on the label to prove a record is the original pressing and not a reissue. To spend hundreds or even thousands of dollars on a rare record or vintage garment, one must believe the seller's assessment of its worth. The authenticity of the vintage goods for sale circulates in tight feedback loops with the credibility of sellers; listing labor connects the two. The style of the platform, along with the messaging of the content, must work together to produce a feeling of vintage-ness. 
Like Craigslist and eBay (Lingel, 2019; White, 2012), and as in so much of the platform economy (e.g., Airbnb listings, Tinder profiles), dedicated vintage platforms like Etsy and Discogs rely on images to prove that the objects for sale are as they appear. Sellers also depend on buyers' feedback to prove their reliability, using site-specific ratings systems akin to the review infrastructures on platforms like Amazon and Airbnb. Craigslist and eBay were pivotal for the development of the digital vintage economy, providing consigners with a means of selling directly and fostering peer-to-peer transactions instead of using vintage merchants as middlemen: "[C]ustomers and suppliers [became] competitors on eBay, adding to the supply chain complexity of second-hand retailing" (Parker \& Weber, 2013, p. 1107).

Thus, secondhand platforms and brick-and-mortar shops have a complicated relationship. Vinyl's darkest days as a format coincide with the origins of the commercial internet. As the mp3 and file sharing changed music listening and exchange practices, new sites like eBay and Craigslist also offered a bonanza of used records at bargain prices, a veritable wild west for virtual crate digging. In the early 2000 s, in cities across the United States, an older generation of independent record stores and vintage boutiques closed as online sales and big box retailers like Walmart and Best Buy replaced in-person browsing at locally owned shops. More recently, even large retail stores have folded, as digital platforms offering on-demand music streaming or fast, free shipping have become the norm: the last Tower Records store in the United States, on Manhattan's West Side, closed in 2006, and Lord and Taylor's Manhattan flagship is now home to WeWork.

Despite retail's setbacks, new waves of boutique stores continue to crop up from Portland to Brooklyn, sustained by thriving subcultures associated with vintage clothing and vinyl record collecting. Vintage shops help make cities and neighborhoods into destinations for shopping and tourism, bolstering local economies. Shop owners may hire local designers and advertise in local media while maintaining relationships with other local merchants and vendors (Parker $\&$ Weber, 2013). On the other hand, boutiques are often in hip neighborhoods, which means that vintage clothing and record shops are also associated with gentrification, simultaneously contributing to rising commercial rents and the displacement of communities of color (Lloyd, 2010; Smith, 1996; Zukin et al., 2009). Shopping local or supporting small boutiques may apply to a small subset of newer hipster shops, whereas earlier Black-owned businesses are overlooked.

Markets for rare vintage goods are predicated on privilege. While dollar bins of records and cheap vintage finds persist at thrift stores and flea markets, curated stores sell high-end vintage clothing and collectible records meant to complement a cultivated lifestyle. Rare punk and soul singles sell for thousands of dollars, circulated globally among cadres of wealthy, dedicated collectors, while vintage aesthetics reinforce gender norms and white beauty ideals. Vintage shapewear, dresses, and skirts are the most commonly sold vintage fashion items (Cassidy \& Bennett, 2012, p. 254). For femmes who collect vintage clothing from the early to mid-20th century, when corsets and girdles narrowed women's waists, vintage shapewear is necessary to achieve the pinup aesthetic (Cassidy \& Bennett, 2012). Yet, as Ulrika Dahl (2014) has noted, drawing on critiques by indigenous fashion bloggers, not everyone wants to uncritically flaunt pinup girl style despite its association with queer subcultures like burlesque: "vintage both reflects and queers a broader cultural imaginary wherein femininity, especially in its palatable and nostalgic 1950s version, remains racialized and more importantly, links 'high femininity' to histories of imperialism and nationalism" (Dahl, 2014, p. 605). Radhika Gajjala (2015) offers a similar critique of the "New Domesticity" trend of young women learning and sharing traditional crafts, such as canning and crocheting, and its commercialization on Etsy. While these cultures rely on digital technologies and contemporary social structures, they are inflected by nostalgia for the past. Implicated in this nostalgia, as Gajjala exposes, are desires to return to imagined traditional gender roles and to white supremacy.

No less than consumption trends, the affordances of specific online platforms shape labor practices within the digital vintage economy, reinforcing gender and racial hierarchies. For instance, eBay's categories can reinforce heteronormativity by classifying queer-centered items as "kink" and perpetuate stereotypes in auctions for racist kitsch (White, 2012). Craigslist became a major platform for peer-to-peer exchange, in part by allowing for anonymity when trading or selling secondhand items, as opposed to newer platforms like VarageSale, which emphasizes a feminized, "cute" entrepreneurial aesthetic (Lingel, 2019). Meanwhile, Etsy is structured by hierarchies and exclusion, and even racist assumptions such as the racialized kitsch displayed on eBay and assumptions of whiteness within crafting circles, leading to crafters of color using white models in their Etsy shops (Close, 2018, p. 880) alongside the ways that anti-Asian sentiments are imbricated in the presentation of handmade goods on sites like Etsy, which are perceived as ethical alternatives to "Made in China" mass-produced commodities (Close \& Wang, this issue). Through platform infrastructures related to race, gender, sexuality, and class-based assumptions about users, the digital vintage economy can reinforce existing social inequalities.

\section{Listing Labor Management}

In the two remaining sections, we outline the ways that platformization is affecting listing labor in the digital vintage economy for both shop owners as entrepreneurs and shop clerks as employees. We describe new challenges for brickand-mortar stores, distinguishing how the performance of listing labor is different on platforms dedicated to selling 
records versus clothing. Shop clerks and owners both have to reconfigure their listing labor practices to balance physical and digital storefronts, but entrepreneurs and employees are differently invested in their work. Employees described the struggle to keep up with the volume of customers' demands and inquiries communicated online, while entrepreneurs articulated their concerns and calculations about whether or not it was worth it to maintain a physical shop.

Vintage goods require upkeep and care, which affects listing labor along with physical labor practices in stores. Vintage clothing needs regular mending, delicate washing, and steaming. Vinyl records must be protected from scratches and kept from sunlight, heat, dust, and mold. Some patina might enhance the authentic feel of a vintage garment, and occasional crackling on a record may charm some listeners, but collectors must maintain the overall health of their treasures. Repair and maintenance tasks help distinguish listing labor in the digital vintage economy from work in other retail sectors. Online listings of a used record's condition provide two grades (e.g., $\mathrm{VG}+/ \mathrm{G}$ ), one for the record itself and one for the packaging - the cover, sleeve, and any additional materials such as liner notes or posters. Listings for especially rare records may include a digital sound clip, so potential buyers can aurally as well as visually sample its condition. For clothing and accessories, online sellers are careful to disclose any fading, holes, or other imperfections. In both cases, not listing the flaws up front could trigger a return, which would increase shipping costs for the seller.

In the digital vintage economy, the mutually constituted authenticity of goods and sellers means that negative reviews can be more costly than returns. For used records and vintage clothes sold online, the most common complaints from buyers are damage during delivery and a condition not measuring up to the posted description. One reviewer of an Etsy store wrote, "Would have been good to have the approximate shoulder width, sleeve length and sleeve opening size included" as the sleeve opening was too small. Their otherwise positive review gave four stars instead of seller's typical five-star rating, prompting the owner to add a disclaimer instructing customers to ask questions about the shop's oneof-a-kind wares, emphasizing her position as a small business owner. Listing labor within the digital vintage economy requires meticulous attention to detail not needed when customers can see items in person, touch them, try them on, or hear them. Many merchants in the digital vintage economy try to preempt negative reviews; it is not uncommon for sellers to post pleas along the lines of this one on Discogs from a seller located in Brazil: "If you are unsatisfied for any reason PLEASE CONTACT ME BEFORE LEAVING ANY FEEDBACK, THERE'S ALWAYS A FAIR AND HAPPY MANNER TO SOLVE ANY PROBLEM ..." The fact that many of this seller's sales involve international shipping, with its higher rates, longer delivery times, and more potential for damage, only heightens the stakes of their "seller rating," aggregated from buyers' feedback. (Discogs members are also assessed with a "buyer's rating," based on sellers' feedback, a more democratizing feature than found on Etsy.) In the digital vintage economy, the added expenses of refunds and return shipments are often worth absorbing to ensure that reviews remain positive.

In addition to making or breaking sellers' reputations, the platformization of the digital vintage economy is also affecting how they settle on prices. Today, any thrift store or flea market vendor knows which website to consult for their fare's going rates, which helps standardize the prices of vinyl records and vintage goods across geographic regions and between online and brick-and-mortar stores. Discogs and Etsy both embody the centralizing, if not outright monopolizing force of platform capitalism (Srnicek, 2016, p. 92), albeit in different ways and each on a smaller scale than an all-encompassing retailer like Amazon (Khan, 2017).

Increasingly, vintage clothing stores are no longer using Etsy, which requires constant updating after every sale, and are instead encouraging customers to purchase merchandise through Instagram. Store M, a high-end clothing boutique in Oakland, does not have an Etsy store, but posts new acquisitions to Instagram, where they have 30,000 followers from around the world. Customers DM the store account for details or to purchase, providing their PayPal information. Posting a photo on Instagram, rather than listing an item on Etsy, can facilitate a faster sale, and can extend the listing labor's reach. Anyone scrolling through Instagram may happen upon the vintage item, instead of having to check the store's Etsy site. Vintage garments and accessories are often one-of-a-kind, so their attendant inventory work and listing labor are applied on an individual basis. Vintage clothing vendors might charge slightly more for a rare item on Instagram or in their Etsy store than they would in a brickand-mortar shop, factoring in the time it takes to list the item, shipping costs, and because they are supplying the "ondemand" convenience of having unique treasures at one's fingertips.

Dedicated platforms for vintage goods have increased the number of individual online sellers. Competition for rare collectibles is intense, among sellers as well as buyers (Ayres, 2019), and branded shops who sell online also have to keep their brick-and-mortar prices in line with those found on sites like Etsy or Discogs, despite the higher overhead of running a physical store. While record stores tend to list rare or expensive merchandise online, records tend to cost slightly more in shops than online. This is in part because Discogs' centralized database rewards sellers who price their records to appear at or near the top of available copies sorted by "lowest price." Some record shops promote their online offerings by touting their brick-and-mortar existence. For instance, Store N in Brooklyn offers over 15,000 records for sale via Discogs. In the comments section for each record, Store $\mathrm{N}$ implores shoppers to "BUY FROM A REAL RECORD STORE IN BROOKLYN," highlighting the supposed authenticity of a physical location in a famously cool 
borough. Indeed, "Record Store Day," held on the third Saturday in April since 2007, is predicated on the premise that transactions conducted inside "real" stores are ethically and experientially superior to online purchases (Harvey, 2017; Palm, 2019).

Online sales can both subsidize and cannibalize brickand-mortar stores. In fact, it has become a successful strategy for new record and vintage clothing stores to establish their business online before opening a brick-and-mortar. Furthermore, whether or not a store sells online, social media is a leading mode of promotion that few merchants can afford to neglect. For example, Store $\mathrm{H}$ in Durham sells used records in their store, but only sparingly on Discogs. Nonetheless, every Wednesday, Store H's Instagram followers can see a video of an employee's hands flipping through new arrivals, highlighting the tactility of browsing while utilizing social media's reach. While brick-and-mortar shops and online sales can work in tandem, moving the entire store online is often easier for shop owners. At a brick-and-mortar location, small business owners have to employ workers to cover the shop while they go out to look for more secondhand merchandise, which involves going to yard, garage, or estate sales and thrift shops, painstakingly digging through Goodwill bins before other sellers nab the best goods (Ayres, 2019), scouring eBay or Craigslist for deals, or meeting with individual consigners. As both owners and employees noted, standing in a store is physically tiring and monotonous, and shop owners who cannot afford to pay clerks may find themselves stuck in their shops five or more days a week. Several owners $(n=3)$ have identified this staffing requirement as a leading factor behind their decision to move to online sales only, which often renders clerks' jobs obsolete.

The trajectory of Store $\mathrm{W}$ in Portland from mobile trailer to brick-and-mortar vintage clothing boutique to Etsy store demonstrates the changes wrought by platformization. Store W's owner employed one part-time clerk, but she worked the majority of shop hours herself to save money. Keeping the shop open 6 days a week and almost never taking a day off made her feel "trapped." In addition to spending time at estate sales, thrifting, or on buying trips in cheaper rural areas, she managed her Etsy store, where she posted pricier items. She eventually closed her brick-and-mortar store and transitioned to selling online only. Her Etsy store, however, is still technically based in Portland, lending her the cache of a hip location, and features images from her original vintage trailer as well as her brick-and-mortar location. She posts new merchandise on Instagram, tagging interested parties to let them know when she is about to list the items on Etsy. Clothing that may have languished on the hanger for months can be sold in minutes, to an online clientele that is much larger than walk-ins and regulars. This more attentive and motivated customer base leads to a more reliable revenue stream that can absorb the shipping costs that accrue to online sales, which themselves are usually a fraction of the rent, insurance, and wages required to run a store.
Platformization affects local businesses and economies, influencing shop owners' calculations about whether or not to keep a physical store open and producing new forms of listing labor tied to social media promotion, digital store fronts, and online ratings systems.

\section{Selling Vintage Selves}

Retail sales work has always included the management of affect as well as inventory (Benson, 1988) and in this final section we describe how platformization can exacerbate as well as alleviate the personal aspects of listing labor in the digital vintage economy. Authenticity is paramount in the digital vintage economy, and listing labor requires the authentication of not only merchandise for sale but also the people selling it. Not unlike the role of authenticity in fashion blogging (Marwick, 2013), listing labor bridges the commercial and the affective, and for entrepreneurs especially, performing an authentic self is essential to success (Duffy, 2017). In the digital vintage economy, store owners and employees often appear in photos and videos for the shop's Instagram and Facebook presence, and the performance of authenticity means that they must embody the right vintage look while projecting a desirable affect. Instagram Stories provide an intimate if fleeting connection between customers and merchants, as store personnel dance near a spinning record or a clerk models a vintage skirt, twirling the fabric for effect. Indeed, Duffy and Pruchniewska's (2017) elaboration of "a digital double bind" applies to many workers in the digital vintage economy, whose jobs are structured through what they define as "soft self-promotion," "interactive intimacy," and "compulsory visibility" (p. 845).

The digital vintage economy creates new forms of labor and visibility for shop clerks, subjecting them to the temporal machinations of platformization while also appropriating and branding their personal style. This can lead to new forms of exploitation of listing labor beyond the day-to-day tasks, which themselves can be emotionally exhausting and physically demanding. For instance, boxes of vinyl records are extremely heavy, vintage boutiques require workers to stand on ladders and use hooks to reach wall items, and workers regularly sweep, dust, and mop. As Duffy and Hund (2015) found in their analysis of influencer culture, online entrepreneurs often show themselves working through consumption, balancing their lifestyle with productivity. Within the context of the digital vintage economy, store owners and clerks will photograph themselves soaking or cleaning items or packing and shipping inventory while also portraying themselves enjoying their time in the shop, posing with new acquisitions, or in curated spaces outside the shop, such as parties or other aesthetically rich events, like pop-up shops or DJ nights at local bars.

Meanwhile, the pace of social media demands that vintage vendors keep generating content, even if they do not have new items coming in. A lack of new merchandise to 
display can generate pressure on owners and employees alike to share personal details and photograph themselves. But unlike influencer culture, this self-presentation and curated sharing is tied to material goods that not only have to be promoted and used, but procured, displayed, sold, packaged, and shipped. Workers in the digital vintage economy promote their own bodies, personalities, and lives as part of their listing labor, not to attract or satisfy sponsors and advertisers, but to attract customers; 10,000 Instagram followers will not help their bottom-line if nobody buys anything. Shop owners and clerks in the digital vintage economy are not necessarily interested in crafting online personas and may in fact be opposed to new technologies as part of their vintage aesthetic. Several shop owners, for instance, do not have Wi-Fi in their stores and conduct in-store transactions through archaic machines instead of using Square. Still, once a shop begins selling online, or even if they just turn to social media to attract customers to their physical location, entrepreneurs find themselves searching for new ways of producing content and promoting themselves to remind customers of their existence.

Given the gendered division of labor within the digital vintage economy, these modes of self-presentation and performed intimacy are especially common in women-owned and women-staffed vintage clothing boutiques. As with many of the listing labor tasks described already, the contemporary presentation of listing laborers online has a deep brick-and-mortar history. "Shop girl" is a vernacular term used by vintage clothing store employees and owners alike, partly tongue-in-cheek, harking back to an imagined earlier era and playing on gender stereotypes. Several vintage clothing boutiques have advertised their need for new "shop girls" on Instagram and post their past and current "shop girls" wearing vintage threads in the store. Histories of the shop girl remark on the role of embodiment and projected fantasy in retail labor; at the turn of the last century, the shop girl "mediated the desires of consumers on the other side of the counter, be they women who wanted to purchase the items on display or men who might desire the shopgirl herself as another type of merchandise" (Sanders, 2006, p. 1). Rather than merely appealing to customers in stores, digital vintage economy workers' images may be circulated far and wide; in the most stylish vintage boutiques, clerks also act as models on Instagram and Etsy. Clerks in vintage stores are often young, thin, and conventionally attractive or photogenic, which is not a great departure from expectations for shop girls in the Victorian era through the high-end department stores and boutiques of the present day. However, their images on the same platforms that they also use to facilitate sales and interact with customers. Their personal Instagram handles are often tagged in these shop-related photoshoots, narrowing the separation between work and personal life. They are not paid for this modeling work and, unlike vintage fashion and/or music bloggers who may provide free advertising for local vintage boutiques by taking photos and tagging shops, low-wage store clerks are not necessarily connected to influencer culture and do not directly benefit.

We should emphasize that shop staff are typically minimum wage workers who do not receive health insurance through their jobs. Their positions are generally part-time and they are often paid under the table, sometimes with discounted merchandise, so there are no official records for tax purposes. One vintage clothing shop worker, a first-generation college student, realized this when she went back to school and applied for financial aid, but had no way of proving her income.

In addition to the shifts they spend at the store, clerks who use their personal devices and sometimes their own social media accounts to interact with customers may find their workdays expanded. Now, they are responding to DMs while not technically on the clock. Not only that, but the longer process from sale to delivery includes packing, shipping, and tracking, and culminates with reviews and online ratings. Intermediaries like PayPal expand listing labor's time horizons further still while also creating new elements of risk. Customers may impulsively buy a coveted object through an Instagram DM or on Discogs, but never follow through with their PayPal details or respond to the merchant's request. If the customer fails to pay, the item must be posted and listed yet again, creating more labor for shop workers. On-demand convenience for consumers means that shop workers must be constantly available, but that each individual sale often takes longer. This exposes the "power-chronography" inherent to listing labor (Sharma, 2014). PayPal adds to workers' workload and anxiety while increasing risk in a way that cash or credit cards do not, calling into question the so-called ease of the newest wave of app-direct purchases in the digital vintage economy.

Listing labor demands the kind of emotional labor Arlie Hochschild (1983) famously associated with flight attendants. Like other retail and service workers, the people working in boutique vintage and record stores are expected to cater to customers and maintain friendly composure no matter how they are treated, especially in women-centered clothing boutiques, whereas a certain detached coolness may be more acceptable in record stores. In digital storefronts, shop workers must refresh merchandise while responding to customer's questions and demands around the clock, lest they lose the sale to another online vendor. As negative reviews often show, vintage shop clerks who fail to project friendliness online or off are disparaged, sometimes called out by name. We interviewed one vintage clothing boutique clerk who was fired after a customer complained in a Yelp review about her reading behind the counter. As this admittedly extreme example demonstrates, the demands of emotional labor in record stores and vintage boutiques fall disproportionately on women. The vast majority of workers asked to model vintage clothing are women, while the preponderance of men shopping in record stores means that women workers can endure unwanted attention and interactions. One 
interviewee who worked at both record and vintage clothing shops said she had experienced sexual harassment at both jobs, but that her interactions with men at the record store also included them "mansplaining obvious bands like The Cure" to her. Tellingly, a Facebook post from a woman clerk at Store A in Carrboro, North Carolina, suggesting that "record shops should have one day a week where white men are prohibited from shopping," generated 60 likes, loves, and laughs, and 28 comments.

One commenter on the thread suggested that "dudes who can't mind their own business should just never be allowed to shop outside of the internet," and while this prohibition would relieve some of the stress imposed upon women inside physical stores, it ignores how online communication remediates rather than alleviates the emotional demands of listing labor. In Oakland, one vintage furniture and clothing shop owner we interviewed lamented, "I hate taking photos for Instagram," but to take a break from posting might mean that the fickle algorithmic gods stop favoring their store, so their usual customer base won't see their content. Some vintage sellers have pointed to the stress created by this new selling system and additional layers of work. A Portland-based vintage jewelry and clothing shop owner posted a selfie and a description of her listing labor fatigue on Instagram. She later deleted the post after several followers chastised her, but then reposted it as a way of pushing back against this affect management:

I posted this selfie a few days ago, trying to capture how hard it is to authentically self promote on IG [Instagram], to come up with images, be part of my own feed and share my struggles as a real person and a business owner and designer. I do not have a social media person doing the work for me. I had some negative comments that made me delete my post.

The shop owner's initial removal of a post in response to negative comments reveals another level of emotional labor involved with the selling of merchandise on digital platforms. Sellers are expected to be cheerful, providing glimpses of their curated homes and cute pets, but they must be careful not to disclose anything controversial, especially about their own labor conditions. Vintage entrepreneurs may selectively share information about shoplifters or delinquent consigners as well as personal details, including the loss of loved ones or breakups. But it is hard for them to know which posts will result in positive attention versus which will attract online hate.

In addition to sharing without oversharing, workers, and especially owners, must be able to write and communicate well, a problem for those who do not have formal training or education. ${ }^{1}$ Chatting with customers is a different skill than writing artfully about rare vintage items or communicating effectively through messaging systems. Some shop owners have enough technical and creative expertise of their own to maintain their online presence, while others rely on hired social media consultants or their shop clerks who perform supplementary listing labor without additional pay. The skills required to balance the physical demands of brick-and-mortar sales and the care of vintage items with curated online content and influencer chic can heighten existing social hierarchies within the digital vintage economy.

\section{Conclusion}

Listing labor in the digital vintage economy demonstrates that "platform labor" includes employees and entrepreneurs utilizing platforms to sell goods, alongside those workers whose labor and other resources are being sold directly on a platform (van Doorn, 2017). Delineating listing labor provides another angle for thinking about the ways that identity-based distinctions such as class, race, and gender condition the opportunities associated with platform labor. Beyond contract, gig, or supplementary labor performed through Airbnb, Uber, TaskRabbit, and UpWork, or hidden labor associated with Amazon Mechanical Turk, warehouse and supply chain labor, and content moderation (Gray \& Suri, 2019; Roberts, 2019), listing labor in the digital vintage economy shows how even more supposedly traditional retail jobs are being reconfigured by changing expectations associated with platformization. Listing labor may not be directly organized through a particular platform, but platformization directly influences what it means to work in the digital vintage economy.

The digital vintage economy circulates rarified material artifacts associated with pre-digital forms of production. Listing labor entails animating online inventory with an aura of authenticity. Our delineation of listing labor in the digital vintage economy, as a specific mode of "platform labor," has revealed two key insights, both of which build on and extend critiques of the platformization of cultural production more broadly:

1. The aged artifacts for sale in the digital vintage economy provide a different perspective toward the "fundamental contingen[cy]" of cultural commodities when their trafficking and/as their production undergoes platformization (Nieborg \& Poell, 2018, p. 4275). Sales in the digital vintage economy are predicated on the verification of sellers as well as their merchandise as authentic.

2. Our analysis of dedicated platforms in digital vintage economy, such as Etsy and Discogs, demonstrates how the platformization of cultural traffic is unfolding with more scaler complexity than is often allowed for in critiques of monolithic corporate giants like Apple or Amazon (Arditi, 2015; Khan, 2017). Alongside analyses of specific labor pools grappling with platformization, such as taxi and livery drivers negotiating ride-sharing apps like Uber and Lyft (Dubal, 2017; Rosenblat, 2018), a focus on cultural labor, more specifically, can help account for the 
ways in which platformization is affecting local economies by contributing to gentrification as well as to unemployment and underemployment.

Such insights from our analysis of listing labor in the digital vintage economy can inform further studies of the platformization of cultural production.

Listing labor embodies the histories of gender, race, and class-based divisions of retail service labor, and the digital vintage economy contributes to gentrification. Nostalgic consumption affects racialized and gendered listing labor while affecting urban socioeconomic patterns of displacement and rising commercial rents. Discogs is part of the growing "Silicon Forest" in Portland, while platforms like Discogs contribute to the economies of scale that lead many shops, including many in Portland, to close, relocate, or move online. Future research into the "platformization of cultural production" should address platforms like Discogs, Etsy, eBay, and Instagram as workplaces and employers, with their own interior cultures as well as external impacts on market sectors and labor pools. The digital vintage economy provides another angle for thinking about the ways that class and identity-based distinctions, along with their intersections with historical forms of discrimination, affect the opportunities associated with platform labor (Noble, 2018), and it highlights the need for studies of platform labor that contextualize it within specific local economies as well as within job markets and economic sectors.

Just as retail and service work require mundane, physical tasks from standing and smiling to sweeping, vinyl records, and vintage clothing are tangible objects, decidedly not digital in nature. Their value is associated with agedness, authenticity, and materiality, attributes that collide with the logics of "contingent" commodification within the growing platform economy (Nieborg \& Poell, 2018). Clothing boutiques and record stores are certainly distinct from colonizing corporations like Uber and Airbnb, but, as we have shown, they do not sit outside of platformization any more than they are being eliminated by it.

\section{Declaration of Conflicting Interests}

The author(s) declared no potential conflicts of interest with respect to the research, authorship, and/or publication of this article.

\section{Funding}

The author(s) received no financial support for the research, authorship, and/or publication of this article.

\section{ORCID iD}

Tamara Kneese (iD https://orcid.org/0000-0001-9905-5914

\section{Note}

1. Similarly, Ticona and Mateescu (2018) have shown how older or not formally educated care workers have trouble transitioning to Care.com or other online platforms for domestic and reproductive labor.

\section{References}

Appadurai, A. (1988). The social life of things: Commodities in cultural perspective. Cambridge University Press.

Arditi, D. (2015). iTake-over: The recording industry in the digital age. Rowman \& Littlefield.

Ayres, J. (2019). The work of shopping: Resellers and the informal economy at the goodwill bins. Business History, 61(1), $122-154$.

Barry, E. (2014, April 30). Digilog culture and the vinyl revival of the early 21 st century. American History Now: Explorations in Digital Curation. http://americanhistorynow.org/2014/04/30/ digilog-culture-and-the-vinyl-revival-of-the-early-21st-century/

Benson, S. (1988). Counter cultures: Saleswomen, managers, and customers in American department stores 1890-1940. University of Illinois Press.

Bonini, T., \& Gandini, A. (2019). First week is editorial, second week is algorithmical: The new gatekeepers of the music industry. Social Media +Society, 5. https://journals.sagepub. com/doi/full/10.1177/2056305119880006

Cassidy, T. D., \& Bennett, H. R. (2012). The rise of vintage fashion and the vintage consumer, fashion practice. Fashion Practice, 4(2), 239-261.

Clark, H., \& Palmer, A. (2005). Old clothes, new looks: Secondhand fashion. Bloomsbury.

Close, S. (2018). Knitting activism, knitting gender, knitting race. International Journal of Communication, 12, 867-889.

Close, S., \& Wang, C. (this issue). International platforms, international prejudice in the cultural production of handmade crafts. Social Media + Society.

Dahl, U. (2014). White gloves, feminist fists: Race, nation and the feeling of "vintage" in femme movements. Gender, Place \& Culture, 21(5), 604-621.

Dubal, V. (2017). Wage slave or entrepreneur? Contesting the dualism of legal worker identities (105 Cal. L. Rev.101; UC Hastings Research Paper No. 176). https://papers.ssrn.com/ sol3/papers.cfm?abstract_id $=2796728$

Duffy, B. E. (2017). (Not)getting paid to do what you love: Gender, social media, and aspirational work. Yale University Press.

Duffy, B. E., \& Hund, E. (2015). "Having it all” on social media: Entrepreneurial femininity and self-branding among fashion bloggers. Social Media + Society, 1(2), 1-11.

Duffy, B. E., \& Pruchniewska, U. (2017). Gender and self-enterprise in the social media age: A digital double bind. Communication \& Society, 20(6), 843-859.

Gajjala, R. (2015). When your seams get undone, do you learn to sew or to kill monsters? The Communication Review, 18(1), 23-26.

Gill, R., \& Pratt, A. (2008). In the social factory? Immaterial labour, precariousness and cultural work. Oncurating, 16/13, 26-40.

Gray, M., \& Suri, S. (2019). Ghost work: How to stop Silicon Valley from building a new global underclass. Houghton Mifflin Harcourt.

Harvey, E. (2017). Siding with vinyl: Record Store Day and the branding of independent music. International Journal of Cultural Studies, 20(6), 585-602. 
Hochschild, A. (1983). The managed heart: Commercialization of human feeling. University of California Press.

Khan, L. (2017). Amazon's antitrust paradox. The Yale Law Journal, 126, 710-805.

Lingel, J. (2019). Socio-technical transformations in secondary markets: A comparison of craigslist and VarageSale. Internet Histories, 3(2), 162-179.

Lloyd, R. (2010). Neo-bohemia: Art and commerce in the postindustrial city (2nd ed.). Routledge.

Luckman, S. (2013). The aura of the analogue in a digital age: Women's crafts, creative markets and home-based labour after Etsy. Cultural Studies Review, 19(1), 249-270.

MacLellan, L. (2018, October 16). The Sears mail-order catalogue subverted Jim Crow-era racism. Quartz. https:/qz.com/ work/1425905/the-sears-mail-order-catalogue-subverted-jimcrow-era-racism/

Marwick, A. (2013, July 7). "They're really profound women, they're entrepreneurs": Conceptions of authenticity in fashion blogging [Paper presentation]. ICWSM, International Conference on Weblogs and Social Media, Cambridge, MA, United States.

McRobbie, A. (2010). Reflections on feminism, immaterial labour, and the post-Fordist regime. New Formations, 70, 60-76.

Nieborg, D. B., \& Poell, T. (2018). The platformization of cultural production: Theorizing the contingent cultural commodity. New Media \& Society, 20(11), 4275-4292.

Noble, S. (2018). Algorithms of oppression: How search engines reinforce racism. New York University Press.

Palm, M. (2017). Technologies of consumer labor: A history of selfservice. Routledge.

Palm, M. (2019). Keeping what real? Vinyl records and the future of independent culture. Convergence: The International Journal of Research into New Media Technologies, 25(4), 643-656.

Parker, B., \& Weber, R. (2013). Second-hand spaces: Restructuring retail geographies in an era of e-commerce. Urban Geography, 34(8), 1096-1118.

Petrusich, A. (2014). Do not sell at any price: The wild, obsessive hunt for the world's rarest 78 rpm records. Scribner.

Roberts, S. (2019). Behind the screen. Yale University Press.

Rosenblat, A. (2018). Uberland. University of California Press.

Sanders, L. (2006). Consuming fantasies: Labor, leisure, and the London shopgirl, 1880-1920. Ohio State University Press.

Seaver, N. (2017). Algorithms as culture: Some tactics for the ethnography of algorithmic systems. Big Data \& Society, 4(2), 1-12.

Sharma, S. (2014). In the meantime: Temporality and cultural politics. Duke University Press.

Sherman, R. (2007). Class acts: Service and inequality in luxury hotels. University of California Press.
Smith, N. (1996). The new urban frontier: Gentrification and the revanchist city. Routledge.

Srnicek, N. (2016). Platform capitalism. Polity.

Stark, L., \& Levy, K. (2018). The surveillant consumer. Media, Culture \& Society, 40(8), 1202-1220.

Straw, W. (1997). Sizing up record collections: Gender and connoisseurship in rock music culture. In S. Whiteley (Ed.), Sexing the groove: Popular music and gender (pp. 3-16). Routledge.

Thorén, C., Edenius, M., Erikkson Lundström, J., \& Kitzmann, A. (2017). The hipster's dilemma: What is analogue or digital in the post-digital society? Convergence: The International Journal of Research into New Media Technologies, 25(2), 324-339.

Ticona, J., \& Mateescu, A. (2018). Trusted strangers: Carework platforms' cultural entrepreneurship in the on-demand economy. New Media \& Society, 20(11), 4384-4404.

Turner, F. (2006). From counterculture to cyberculture: Stewart Brand, the Whole Earth network, and the rise of digital utopianism. University of Chicago Press.

van Doorn, N. (2017). Platform labor: On the gendered and racialized exploitation of low-income service work in the "ondemand" economy. Information, Communication \& Society, 20(6), 898-914.

White, M. (2012). Buy it now: Lessons from eBay. Duke University Press.

Williams, C. L., \& Connell, C. (2010). "Looking good and sounding right": Aesthetic labor and social inequality in the retail industry. Work and Occupations, 37(3), 349-377.

Zukin, S., Trujillo, V., Frase, P., Jackson, D., Recuber, T., \& Walker, A. (2009). New retail capital and neighborhood change: Boutiques and gentrification in New York City. City \& Community, 8(1), 47-64.

\section{Author Biographies}

Tamara Kneese (PhD, New York University) is assistant professor in the Department of Media Studies and Program Director of Gender and Sexualities Studies at the University of San Francisco. Her research interests include mediated mourning rituals, digital care work and labor practices, and structural inequality in Silicon Valley.

Michael Palm (PhD, New York University) is associate professor of Media and Technology Studies and director of Graduate Studies in the Department of Communication at the University of North Carolina at Chapel Hill. His research interests include the histories of automation and consumer culture, supply chain infrastructures, and critical theories of labor and technology. 